\title{
Especialistas Discutem Uso de Polímeros Naturais e Fibras Vegetais
}

Contando com a presença de cerca de 160 participantes, dentre os quais 45 especialistas estrangeiros de países tais como Estados Unidos, França, Suécia, Polônia, Alemanha, Canadá, Reino Unido, Índia, Chile, Argentina, Equador e outros, o Terceiro Simpósio Internacional sobre Polímeros Naturais e Compósitos- ISNaPol/2000, realizado no período de 14 a 17, no Hotel Colina Verde, em São Pedro-SP, foi coroada de êxito. O evento foi promovido pela Embrapa Instrumentação Agropecuária, vinculada ao Ministério da Agricultura e do Abastecimento, em parceria com o Instituto de Química de São Carlos-USP, a Faculdade de Ciências Agronômicas - UNESP e um grupo de trabalho da FAOOrganização das Nações Unidas.

Foram apresentados cerca de 110 trabalhos mostrando as novidades na preparação, modificação e caracterização de polímeros e fibras naturais por diferentes técnicas de processamento e de fabricação de polímeros naturais e seus compósitos. Durante o ISNAPOL também foi realizado um workshop organizado pelo grupo de trabalho das Nações Unidas sobre o progresso no cultivo, beneficiamento e potencial de mercado do setor de fibras naturais.

Os pesquisadores - Anand Sanadi e Ferencz Denes da Universidade de Wisconsin, Estados Unidos, - Kuruvilla Joseph e Sabu Thomas, da Faculdade de Berchman, Índia, também visitaram as Universidades e Centros de Pesquisas de São Carlos, onde foram acertados projetos de colaboração técnico-científica com pesquisadores brasileiros.

O conteúdo do evento ficou registrado na forma de anais que já foram publicados em 593 páginas (em inglês), conforme mostra a foto. Os interessados nesta área ainda podem aproveitar do conteúdo do evento adquirindo uma cópia dos anais. Para tanto podem contactar o pesquisador Luiz H. C. Mattoso (e-mail: mattoso@cnpdia.embrapa.br).



